\title{
Strengthening the development of Qur'anic schools and student profiles about Pancasila during the pandemic
}

\author{
Yayuk Hidayah \\ Departmet of Primary School Teacher Education, Universitas Ahmad Dahlan, Jl. Kapas No.9, Semaki, Kec. Umbulharjo, Kota Yogyakarta, Daerah \\ Istimewa Yogyakarta 55166, Indonesia \\ yayuk.hidayah@pgsd.uad.ac.id \\ * Corresponding author
}

\begin{tabular}{|c|c|}
\hline ARTICLE INFO & ABSTRACT \\
\hline $\begin{array}{l}\text { Article history } \\
\text { Received: } 2021-02-23 \\
\text { Revised: } 2021-03-23 \\
\text { Accepted: } 2021-03-26 \\
\text { Published: } 2021-04-30 \\
\text { Keywords } \\
\text { Qur'anic school } \\
\text { TPA } \\
\text { The profile of Pancasila Students } \\
\text { Ustadz/Ustadzah }\end{array}$ & $\begin{array}{l}\text { Learning in the mass of the Covid-19 pandemic requires various innovations and management to stay } \\
\text { in line with the direction and goals in education. The purpose of this service is to increase the } \\
\text { understanding of TPA teachers (ustadz / ustadzah) to develop Taman Pendidikan Al-Qur'an/TPA } \\
\text { (Qur'anic school) and learning during the pandemic as well as to strengthen the profile of Pancasila } \\
\text { Students. The service was carried out by a team from the Department of Primary School Teacher } \\
\text { Education, Universitas Ahmad Dahlan during a month. Based on the dedication carried out, it is } \\
\text { known that there has been an increase in understanding of TPA development and learning during the } \\
\text { pandemic. This event also produces TPA management documents. Based on this dedication, it can be } \\
\text { concluded that the understanding of TPA teachers to develop TPA and learning during the pandemic } \\
\text { has increased. It is hoped that the continuity of this service activity is that there is a continuation of } \\
\text { cooperation to increase the understanding of TPA teachers to develop TPA and learning during the } \\
\text { pandemic as well as to strengthen the profile of Pancasila Students. }\end{array}$ \\
\hline \multirow[t]{2}{*}{$\begin{array}{l}\text { Kata kunci } \\
\text { Manajemen } \\
\text { Profil Pelajar Pancasila } \\
\text { TPA } \\
\text { Ustadz/Ustadzah }\end{array}$} & $\begin{array}{l}\text { Penguatan pengembangan TPA dan profil siswa tentang Pancasila di masa pandemi. Pembelajaran } \\
\text { di massa pandemi Covid-19 menuntut berbagai inovasi serta pengelolaan agar tetap selaras dengan } \\
\text { arah serta tujuan dalam pendidikan. Tujuan dari pengabdian ini adalah meningkatkan pemahaman } \\
\text { Ustadz/Ustadzah TPA untuk mengembangkan TPA dan pembelajaran pada masa pandemi serta } \\
\text { penguatan profil Pelajar Pancasila. Pengabdian dilakukan oleh tim dari Program Studi Pendidikan } \\
\text { Guru Sekolah Dasar Universitas Ahmad Dahlan selama } 1 \text { bulan. Berdasarkan pengabdian yang } \\
\text { dilakukan, diketahui bahwa terjadi peningatan pemahaman mengenai pengembangan TPA dan } \\
\text { pembelajaran pada masa pandemi. Kegiatan pengadian ini juga menghasilkan dokumen manajemen } \\
\text { TPA. Berdasarkan pengabdian ini, dapat disimpulkan bahwa pemahaman Ustadz/Ustadzah TPA } \\
\text { untuk mengembangkan TPA dan pembelajaran pada masa pandemi telah mengalami peningkatan. } \\
\text { Diharapkan keberlanjutannya dari kegiatan pengabdian ini ialah terdapat keberlanjutan kerjasama } \\
\text { guna meningkatkan pemahaman Ustadz/Ustadzah TPA untuk mengembangkan TPA dan } \\
\text { pembelajaran pada masa pandemi serta penguatan profil Pelajar Pancasila. }\end{array}$ \\
\hline & $\begin{array}{l}\text { Copyright } \odot 2021 \text {, Hidayah } \\
\text { This is an open access article under the CC-BY-SA license }\end{array}$ \\
\hline D) Check for updates & \\
\hline
\end{tabular}

How to cite: Hidayah, Y. (2021). Strengthening the development of Qur'anic schools and student profiles about Pancasila during the pandemic. Journal of Community Service and Empowerment, 2(1), 28-34. doi: https://doi.org/10.22219/jcse.v2i1.15712

\section{PENDAHULUAN}

Pembelajaran di massa pandemi Covid-19 menuntut berbagai inovasi serta pengelolaan agar tetap selaras dengan arah serta tujuan dalam pendidikan. Selama masa pandemi, berbagai pembaharuan model dan strategi pendidikan telah banyak dilakukan, hal ini terjadi menurut Dayal dan Tiko (2020) pembelajaran di massa pandemi membawa kekhwatiran bagi guru mengenai pribadi mereka dan juga tentang kehidupan profesional mereka sebagai guru. Sampai saat ini, paradigma pendidikan di massa pandemi Covid-19 masih terus mengalami peningkatan dengan pendalaman kajian serta inovasi pada 
dunia pendidikan seperti yang dinyatakan oleh Pokhrel dan Chhetri (2021) dalam kurun waktu singkat setelah pandemi Covid-19, banyak peneliti telah membagikan karya mereka tentang pengajaran dan pembelajaran dengan berbagai cara.

Kebutuhan pendidikan di massa pandemi Covid-19 memerlukan seruan untuk dapat belajar mengenai hal-hal baru dalam dunia pendidikan seiring dengan berjalannya proses pendidikan pada massa pandemi Covid-19. Hasil penelitian pada pengalaman guru dalam melakukan instruksi sinkron dan asinkron selama pandemi Covid-19 dengan melibatkan 133 guru sekolah Dasar dan menengah dari sekolah berbahasa Ibrani dan berbahasa Arab di Israel oleh Shamir-Inbal \& Blau (2021) menghasilkan bahwa berbagai strategi pembelajaran jarak jauh pedagogis yang digunakan oleh meningkatkan kebutuhan untuk mengubah situasi pandemi Covid-19 menjadi berkah dengan memasukkan pengalaman pembelajaran yang ditingkatkan teknologi jarak jauh dan aktivitas online ke dalam agenda sekolah secara teratur. Oleh karena itu, Seruan dalam meningkatkan pemahaman serta inovasi dalam proses pendidikan pada massa pandemi Covid-19 tidak terkecuali juga dibutuhkan oleh Ustadz/Ustadzah sebagai pengajar di Taman Pendidikan Al-Quran (TPA). Mulyasa (2008) menjelaskan jika Ustadz ialah pendidik yang memiliki fungsi sebagai tokoh panutan sehingga seorang Ustadz memiliki standar kualitas pribadi yang meliputi tanggung jawab, mandiri dan disiplin. Ustadz/Ustadzah menjadi komponen utama bagi TPA, seiring dengan penyelengagaraan pendidikan di TPA terutama di massa pandemi Covid-19.

Menindaklanjuti urgensi keterampilan Ustadz/Ustadzah di massa pandemi Covid-19, menjadi salah satu kompetensi yang penting bagi mereka adalah keterampilan dalam mengembangkan manajemen dan penguatan Profil Pelajar Pancasila. Hal ini penting menurut Khan et al (2015) dalam perkembangan jaman yang sangat pesat, kebutuhan akan pengembangan manajemen cukup besar karena pengembangan manajemen adalah cara terstruktur yang untuk meningkatkan keterampilan dan pengetahuan. Dengan keterampilan dalam mengembangkan manajemen, seorang pengajar akan lebih siap mengelola pembelajaran sehingga dapat mengesuaikan dengan kebutuhan serta perkembangan dunia pendidikan. Pandangan tersebut sesuai dengan pendapat Gilmour et al (2018) bahwa dengan keterampilan pengelolaan kelas yang dimiliki guru, bermanfaat mendukung penggunaan strategi manajemen kelas yang baik.

Hal disayangkan ialah berdasarkan hasil wawancara dengan Ustadz/Ustadzah di wilayah Tambakboyo Yogyakarta, pada Bulan Desember 2020 dapat dikatakan bahwa pemahaman mengenai keterampilan dalam mengembangkan manajemen TPA dan Profil Pelajar Pancasila masih kurang. Terlebih dengan Profil Pelajar Pancasila yang masih asing bagi mereka. Temuan ini sejalan dengan hasil dokumentasi yang dilakukan tim pengabdian tentang manajemen dan Profil Pelajar Pancasila di TPA bagi Ustadz/Ustadzah di wilayah Tambakboyo Yogyakarta. Tim pengabdian dapat memaklumi temuan ini karena hal ini terjadi menurut Simonsen et al (2019) para pendidik terbatas dalam pengelolaan kelas, sehingga menjadi kewajiban untuk memberikan dukungan pengembangan profesional yang efisien dan efektif. Selama ini, tidak dapat dipungkri bahwa Ustadz/Ustadzah sebagai pengajar di TPA belum mendapat perhatian yang cukup dalam berbagai tekhnik dan alat yang dapat meningkatkan kemampuan mereka dalam mengelola TPA.

Dari hasil wawancara dengan beberapa Ustadz/Ustadzah di Wilayah Tambakboyo Yogyakarta pada Bulan Desember, tim pengabdian mengetahui bahwa mereka belum cukup memiliki keterampilan dalam manajemen TPA dan Profil Pelajar Pancasila. Sementara pada sisi lainnya, Menteri Pendidikan dan Kebudayaan (Mendikbud) menegaskan jika salah satu jalan mewujudkan pendidikan karakter bagi Mendikbud ialah pelajar Pancasila dimulai dari Pendidikan Dasar hingga Pendidikan Tinggi dengan menggunakan berbagai mekanisme penumbuhan gerakan pendidikan karakter (Antara News.com, 2020). Keterampilan dalam manajemen TPA dan Profil Pelajar Pancasila bagi Ustadz/Ustadzah di Wilayah Tambakboyo Yogyakarta menjadi desain dalam meningkatkan tingkat keterampilan baru mereka sebagai seorang pendidik di TPA. Hal ini sejalan dengan yang sampaikan oleh Chow et al (2020) yang mengungkapkan bahwa manajemen kelas oleh pendidik memberikan kelancaran dalam praktik pendidikan di masa mendatang.

Memperhatikan permasalahan yang dihadapi mitra di Wilayah Tambakboyo Yogyakarta, sudah saatnya perbaikan dan pembaharuan yang bertujuan memotivasi dan mendukungan keterampilan Ustadz/Ustadzah dilakukan. Liu dan Hallinger (2018) mengatakan bahwa dalam menopang pembelajaran yang profesional bagi pendidik, mereka memerlukan motivasi, dukungan. Maka Perbaikan dan pembaharuan mitra di Wilayah Tambakboyo Yogyakarta dapat dimuali dengan memberikan pemahaman Ustadz/Ustadzah TPA untuk mengembangkan TPA dan pembelajaran pada masa pandemi serta penguatan profil Pelajar Pancasila. Dalam konsep pendidikan karakter, Lickona (1991) menyatakan bahwa pendidikan karakter memiliki dasar hukum yang sesuai dengan prinsip ajaran agama dalam kitab suci yang selanjutnya berlaku secara universal sebagai pendidikan akhlak atau pendidikan moral. Salah satu keterampilan yang perlu dikuasai oleh Ustadz/Ustadzah di Wilayah Tambakboyo Yogyakarta ialah keterampilan dalam manajemen TPA dan Profil Pelajar Pancasila agar dalam pembelajaran di TPA selama masa Pandemi, Ustadz/Ustadzah dapat melaksanakan pembelajaran secara inovatif, kreatif dan efisien.

Bertolak dari permasalahan yang di hadapi mitra di Wilayah Tambakboyo Yogyakarta, tim pengabdian kemudian melakukan identifikasi solusi permasalahan agar strategis, terarah dan terencana salah satunya ialah dengan melakukan pelatihan peningkatan pemahaman Ustadz/Ustadzah TPA mengenai manajemen TPA dan penguatan profil Pelajar Pancasila pada masa pandemi. Identifikasi solusi permasalahan mitra tim pengabdian lakukan sejalan dengan pendapat Hamlen (2017) yang mengungkapkan hubungan antara gaya pemecahan masalah umum dan preferensi pemecahan masalah dapat menjadi cerminan dari gaya pemecahan masalah di kehidupan nyata. Berdasarkan hal tersebut, tujuan dari pengabdian ini ialah memberikan pemahaman, pengetahuan dan pelatihan mengenai manajemen TPA dan penguatan 
profil Pelajar Pancasila pada masa pandemi. Kegiatan pengabdian berupa kegiatan worskshop, ceramah dan diskusi mengenai keterampilan manajemen TPA dan penguatan profil Pelajar Pancasila.

Tujuan penulisan artikel ini ialah memberikan detail informasi mengenai pelaksanaan pengabdian yang mampu memberikan pemahaman pada Ustadz/Ustadzah untuk mengembangkan TPA dan pembelajaran pada masa pandemi serta penguatan pada aspek perofil pelajar Pancasila. Detail informasi dalam artikel ini tim peneliti sesuaikan dengan pendapat Kabir (2016) bahwa laporan penelitian ialah untuk menghasilkan pengetahuan baru yang pada akhirnya dapat menghasilkan kemakmuran suatu bangsa. Keberhasilan implementasi pengabdian ini menjadi informasi yang penting bagi dunia pendidikan mengingat TPA dan Ustadz/Ustadzah menjadi bagian pendidik profesioanl yang memiliki tanggung jawab dalam mengarahkan dan membimbing para santri sebagai generasi muda seperti yang kemukakan oleh Daradjat (2008) bahwa pendidik professional ialah mereka yang merelakan dirinya dalam memikul tanggung jawab sebagai orang tua untuk para santri mereka.

Program pengabdian pemahaman Ustadz/Ustadzah TPA untuk mengembangkan TPA dan pembelajaran pada masa pandemi serta penguatan profil Pelajar Pancasila berfokus pada kompetensi Ustadz/Ustadzah yang secara nyata dapat bermanfaat serta berkontribusi dalam pencapaian penguatan profil Pelajar Pancasila dan pengembangan TPA dan pembelajaran pada masa pandemi. Garcia et al (2020) menyatakan bahwa manfaat serta kontribusi dari fokus permasalahan dapat menentukan merencanakan dan menemukan sumber informasi dari pemecahan masalah dengan model yang lebih kontemporer. Dalam penulisan artikel ini, pemecahan masalah atas gagapnya santri dalam menyesuikan pembelajaran di masa pandemi tertuang dalam solusi pengabdian pemahaman pada Ustadz/Ustadzah untuk mengembangkan keterampilan manajemen TPA dan serta penguatan pada aspek perofil pelajar Pancasila di masa pandemi Covid-19.

\section{METODE}

Berdasarkan pada situasi yang dihadapi mitra berupa pemahaman Ustadz/Ustadzah TPA di Wilayah Tambakboyo Yogyakarta untuk mengembangkan manajemen TPA dan penguatan profil Pelajar Pancasila masih rendah, tim pengabdian kemudian melakukan kegiatan pengabdian berupa kegiatan worskshop, ceramah dan diskusi mengenai keterampilan manajemen TPA dan penguatan profil Pelajar Pancasila. Secara keseluruhan, kegiatan solutif permasalahan mitra Ustadz/Ustadzah TPA di Wilayah Tambakboyo Yogyakarta dapat dijelaskan pada Gambar 1, yang dilaksanakan pada bulan Februari-Maret 2021.

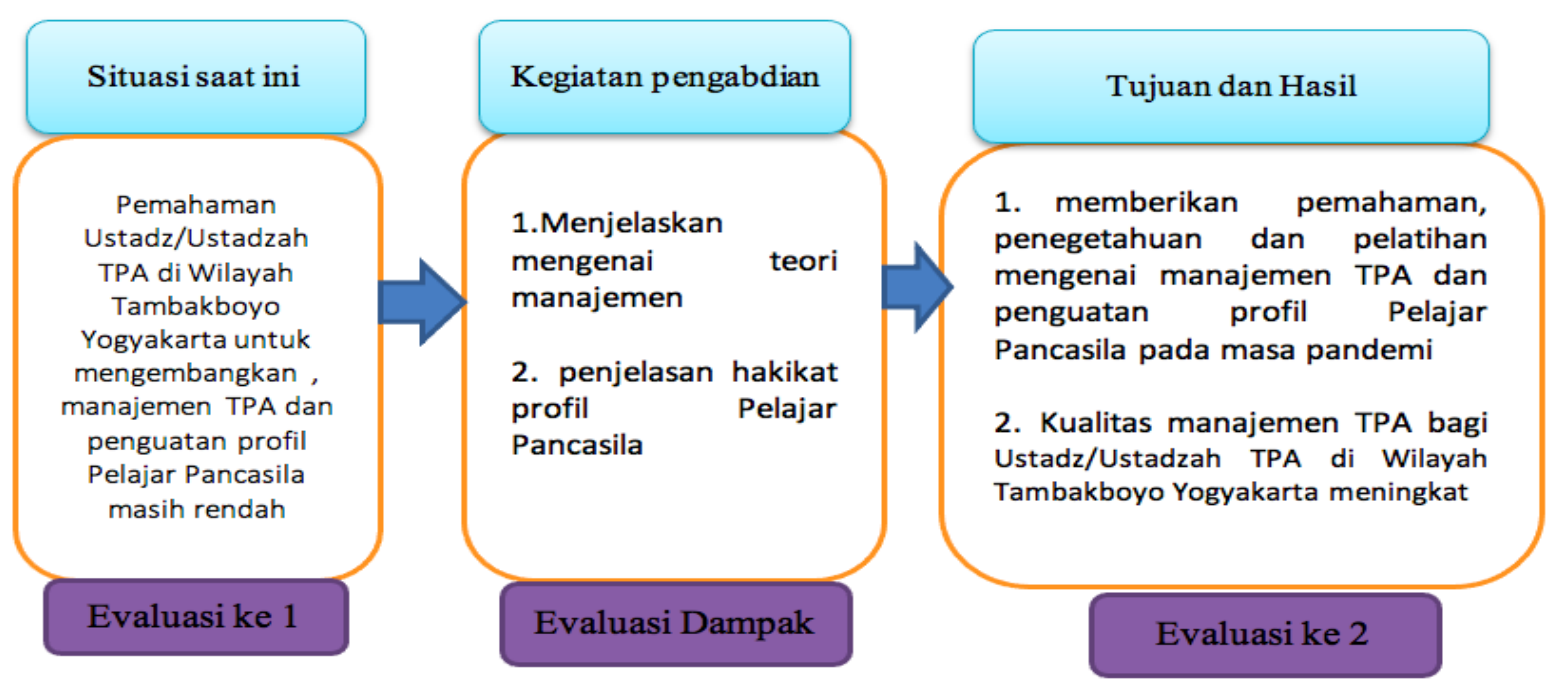

Gambar 1. Alur pengabdian pemahaman Ustadz/Ustadzah TPA di Wilayah Tambakboyo Yogyakarta mengenai manajemen TPA dan profil pelajar Pancasila

Sasaran dalam kegiatan pengabdian ini ialah Ustadz/Ustadzah TPA di Wilayah Tambakboyo Yogyakarta dan pematerinya ialah tim pengabdian dari pogram studi Pendidikan Guru Sekolah Dasar, Universitas Ahmad Dahlan Yogyakarta. Sasaran dalam kegiatan ini peneliti sesuaikan dengan permintaan PCM di Wilayah Tambakboyo Yogyakarta dan juga pendapat Collins, Sibthorp, \& Gookin (2016) bahwa dalam masyarakat yang dinamis, kompleks, dan beragam, kemampuan untuk menyelesaikan masalah menjadi keterampilan yang semakin kritis. Jumlah Ustadz/Ustadzah TPA yang terlibat dalam pengabdian ini ialah sebanyak 25 orang yang berasal dari TPA di Wilayah Tambakboyo Yogyakarta. Guna menjaga efektivitas kegiatan pengabdian, pada kegiatan ini tim membagi menjadi dua tahapan yaitu 1) seluruh Ustadz/Ustadzah yang terlibat dalam pengabdian ini melakukan curah pendapat mengenai keterampilan manajemen TPA dan profil pelajar Pancasila. Curah pendapat dilakukan dengan tujuan mengetahui situasi awal secara objektif mengenai manajemen TPA dan profil pelajar Pancasila di Wilayah TPA Tambakboyo Yogyakarta. 2) seluruh Ustadz/Ustadzah yang 
terlibat dalam pengabdian mengikuti sesi diskusi presentasi materi teori manajemen dan penjelasan hakikat profil Pelajar Pancasila.

Selanjutnya, guna melihat keberhasilan kegiatan pengabdian, tim pengabdian melakukan evaluasi pertama. Penggunaan evaluasi tim pengabdian sesuaikan dengan pendapat Kürzinger et al (2020) bahwa evaluasi secara deskriptif menjadi titik awal untuk penilaian manfaat risiko yang terstruktur. Selain itu, tim pengabdian juga melakukan evaluasi dampak untuk dapat melihat relevansi, efisensi dan efektifitas program dalam pengabdian pada ialah Ustadz/Ustadzah TPA di Wilayah Tambakboyo Yogyakarta. Setelah melakukan evaluasi dampak, kemudian tim pengabdian melakukan evaluasi ke dua yang peneliti sesuaikan dengan pendapat Piggot-Irvine \& Zornes (2016) bahwa penyelidikan dapat menyimpulkan kompleksitas kerangka kerja evaluasi secara menyeluruh yang berbeda. Evaluasi juga tim pengabdian lakukan selama kegiatan presentasi materi teori manajemen dan penjelasan hakikat profil Pelajar Pancasila berlangsung. Selain itu, evaluasi juga dilakukan terhadap kinerja dan tugas dalam pengabdian pelatihan manajemen TPA dan penguatan profil Pelajar Pancasila di Wilayah Tambakboyo Yogyakarta.

\section{HASIL DAN PEMBAHASAN}

Kegiatan pengabdian yang pertama dilaporkan dalam artikel ini ialah tahapan perencanaan. Abe (2005) menyatakan bahwa perencanaan adalah Tindakan dimasa depan sebagai reaksi terhadap masa depan. Pada tahapan perencanaan pelatihan manajemen TPA dan penguatan profil Pelajar Pancasila di Wilayah Tambakboyo Yogyakarta, tim pengabdian melakukan analisis kebutuhan dan pembagian tugas dalam pengabdian. Pelaksanaan tahapan perencanaan pelatihan manajemen TPA dan penguatan profil Pelajar Pancasila di Wilayah Tambakboyo Yogyakarta didahului dengan koordinasi dengan PCM Cabang Wilayah Tambakboyo Yogyakarta. Koordinasi dilakukan dalam rangka memenuhi tuntutan situasional mitra pengabdian seperti yang dinyatakan oleh Henrickson Parker, Schmutz, \& Manser (2018) bahwa koordinasi memiliki fungsi dalam menyesuaikan kinerja untuk memenuhi tuntutan situasional. Kegiatan tahapan awal dilakukan pada Bulan Desember 2020.

Pada tahapan awal perencanaan pelatihan manajemen TPA dan penguatan profil Pelajar Pancasila di Wilayah Tambakboyo Yogyakarta, dibicarakan serta diputuskan formasi tim pengabdian. Pembicaraan tahapan awal pelatihan bermanfaat sebagai usaha dalam pembagian kerja yang kompleks seperti yang dinyatakan oleh Randell et al (2019) bahwa kerja tim yang efektif memainkan peran dalam pembagian kerja yang kompleks. Sebagai hasil dari perencanaan tahap pertama, tim pengabdian terbentuk seperti dalam Tabel 1.

Tabel 1. Materi pelatihan manajemen TPA dan penguatan profil Pelajar Pancasila di Wilayah Tambakboyo Yogyakarta

\begin{tabular}{llll}
\hline No & Pemateri & Materi & Uraian materi \\
\hline 1 & Suyitno, M.Pd & Kurikulum TPA & 1. Teori Kurikulum \\
& & & 2. Kurikulum TPA \\
2. & Yayuk Hidayah, M.Pd & Manajemen TPA & $\begin{array}{l}\text { 1. Teori manajemen } \\
\end{array}$
\end{tabular}

Tahapan kedua dalam pengabdian pelatihan manajemen TPA dan penguatan profil Pelajar Pancasila di Wilayah Tambakboyo Yogyakarta ialah tahapan pembekalan. Pelatihan manajemen TPA dan penguatan profil Pelajar Pancasila tim pengabdian sesuaikan dengan materi pada tabel 1. Pengabdian pelatihan manajemen TPA dan penguatan profil Pelajar Pancasila di Wilayah Tambakboyo Yogyakarta tim lakukan dengan 1) curah pendapat peserta pelatihan yaitu Ustadz/Ustadzah di Wilayah TPA Tambakboyo Yogyakarta, 2) Presentasi materi oleh tim peneliti sesaui dengan Tabel 1 , dan 3) refleksi proses pelatihan, dan 4) pendampingan pelatihan secara daring melalui Group Whatsapp .

Kegiatan pengabdian pelatihan manajemen TPA dan penguatan profil Pelajar Pancasila di Wilayah Tambakboyo Yogyakarta tim lakukan sesuai dengan prinsip terencana, terarah. Hal ini tim pengabdian lakukan berdasarkan pendapat Entin et al (2002) bahwa pelatihan dalam mengidentifikasi kebutuhan informasi akan membantu pengambil keputusan mengenali kebutuhan informasi dan fokus pada kebutuhan daripada surplus informasi. Waktu pelaksaan pengbdian tim lakukan sebanyak tiga kali pertemuan yang dilaksanakan mulai pukul 13. 00 WIB sampai dengan 16.00 WIB secara berkala dalam rentan waktu 1 bulan.

Pada awal kegiatan pelatihan, secara invidual Ustadz/Ustadzah TPA di Wilayah Tambakboyo Yogyakarta melakukan curah pendapat mengenai manajemen TPA dan penguatan profil Pelajar Pancasila di Wilayah Tambakboyo Yogyakarta. Kegiatan curah pendapat tim pengabdian lakukan dengan mengacu pada pendapat Yusuf dan Trisiana (2019) bahwa dalam curah pendapat adalah metode sumbang saran yang terdapat unsur mendukung, melengkapi, atau menyepakati usulan dari masing-masing anggota. Kegiatan pelatihan dilakukan selama 4 jam pelajaran pada februari 2021, kedua Februari 2021 dan pertemuan ke -3 pada Maret 2021. Berdasarkan hasil observasi, Ustadz/Ustadzah terlihat antusias dalam kegiatan pelatihan sesi pemberian materi ini. Metode penyampaian materi dilakukan secara variative oleh tim pengabdian. 


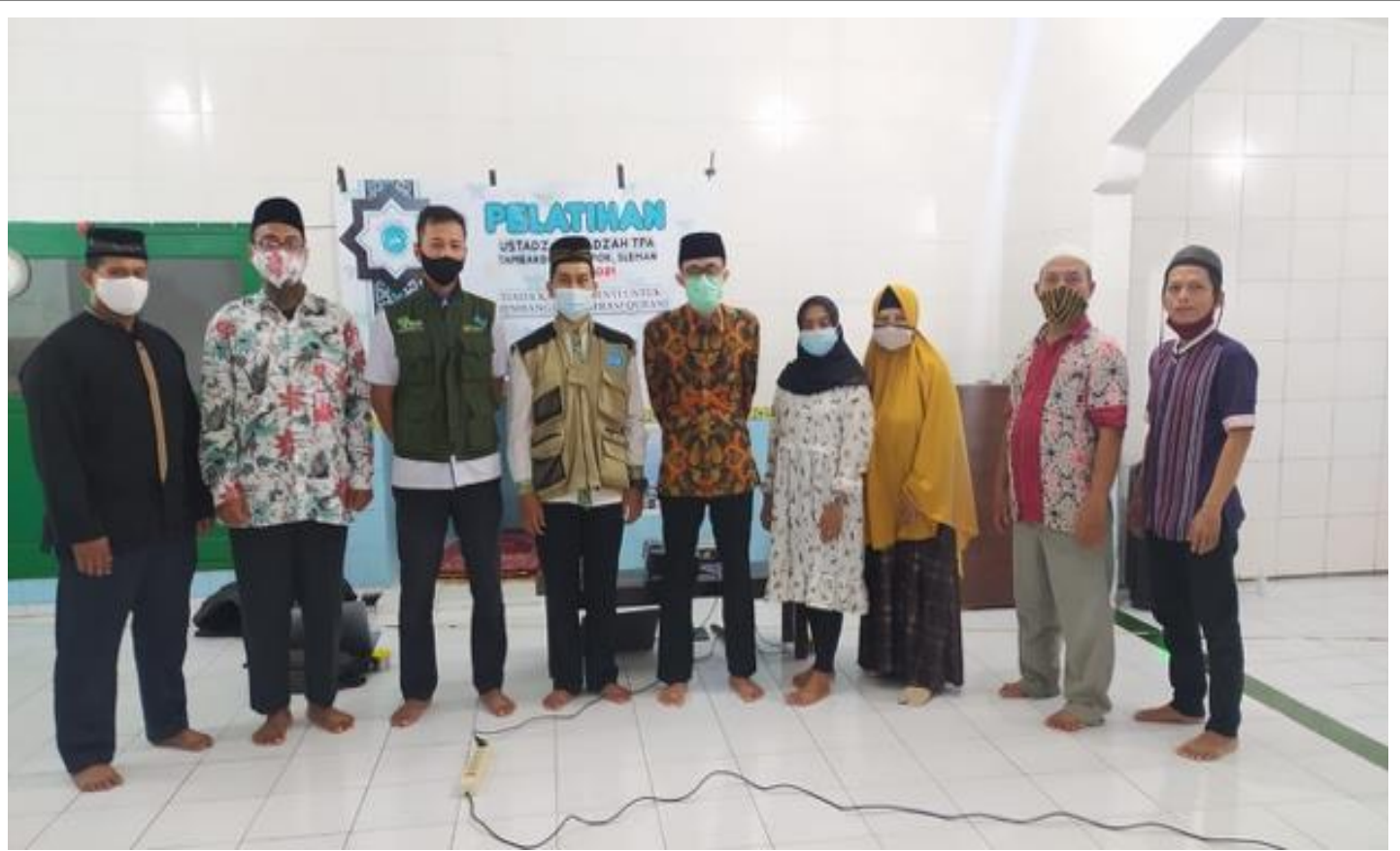

Gambar 1. Foto bersama dengan peserta

Setelah selesai curah pendapat mengenai manajemen TPA dan penguatan profil Pelajar Pancasila di Wilayah Tambakboyo Yogyakarta dari para Ustadz/Ustadzah, tim pengabdian mendapat beberapa fakta bahwa 1) Ustadz/Ustadzah di Wilayah Tambakboyo Yogyakarta memiliki kekurang dalam hal manajemen TPA, 2) Profil Pelajar Pancasila di Wilayah Tambakboyo Yogyakarta masih kurang di ketahui oleh Ustadz/Ustadzah, 3) kurangnya pelatihan manajemen TPA dan Profil Pelajar Pancasila bagi Ustadz/Ustadzah di Wilayah Tambakboyo Yogyakarta.

Setelah melakukan sesi pelatihan, kemudian peserta pengabdian manajemen TPA dan penguatan profil Pelajar Pancasila di Wilayah Tambakboyo Yogyakarta melakukan sesi refleksi. Aktifitas refleksi tim pengabdian lakukan dengan mengacu pada aktivitas evaluasi dalam memberikan nilai dalam objek tertentu seperti yang dinyatakan Sudjana (2009) bahwa evaluasi merupakan proses dalam penentuan nilai dengan menggunakan kriteria tertentu. Pada aktifitas refleksi, peserta pengabdian juga memberikan umpan balik melalui google form, tanya jawab dengan pemateri dan juga mendapat link google drive yang berisi materi selama kegiatan pengabdian manajemen TPA dan penguatan profil Pelajar Pancasila di Wilayah Tambakboyo Yogyakarta berlangsung.

Pada akhir pertemuan kegiatan pengabdian, tim pengabdian melakukan penguatan materi manajemen TPA dan penguatan profil Pelajar Pancasila di Wilayah Tambakboyo Yogyakarta. Penguatan materi tim lakukan dengan harapan dapat meningkatkan motivasi serta perhatian yang mendalam dari peserta pengabdian mengenai materi manajemen TPA dan penguatan profil Pelajar Pancasila. Hardré et al (2013) menyatakan jika proses dan strategi dalam penguatan materi pada suatu pembelajaran dapat megembangan keterampilan, integrasi dan pengembangan masyarakat yang dapat mendukung kesuksesan mereka,dengan demikian dapat mendorong inovasi. Berdasarkan hasil observasi, pada akhir pertemuan kegiatan pengabdian para Ustadz/Ustadzah di Wilayah Tambakboyo Yogyakarta terlihat antusias dan proses diskusi berjalan dengan kondusif. Hal tersebut sudah menjadi tolak ukur dalam keterlibatan belajar dan menunjang keberhasiln kegiatan pengabdianseperti yang dikatakan oleh Hidayah (2020) bahwa dalam belajar, aktivitas keterlibatan adalah pentin.

Pada kegiatan pengabdian ini, penekanan bukan hanya pada materi manajemen TPA dan penguatan profil Pelajar Pancasila tetapi juga pada pemberian materi mengenai kurikulum di TPA. Kegiatan pengabdian yang dilapokan dalam artikel ini secara spesifik pada materi manajemen TPA dan penguatan profil Pelajar Pancasila Ustadz/Ustadzah di Wilayah Tambakboyo Yogyakarta di masa pandemi. Tim pengabdian menyadari bahwa manajemen TPA dan penguatan profil Pelajar Pancasila di masa pandemi mejadi salah satu basis pengetahuan yang penting bagi Ustadz/Ustadzah di Wilayah Tambakboyo Yogyakarta. Jackson dan Miller (2019) menyatakan jika manajemen kelas diidentifikasi sebagai cara dalam memahami dan menerapkan praktik manajemen kelas untuk meningkatkan rasa self-efficacy. Kegiatan pembelajaran TPA di Wilayah Tambakboyo Yogyakarta di masa pandemi selayaknya juga dapat mendorong santri untuk dapat lebih dinasim dan kretatif sehingga terbentuk santri yang cerdas dan memiliki nilai religius.

Selain itu, penguatan profil Pelajar Pancasila pada Ustadz/Ustadzah di Wilayah Tambakboyo Yogyakarta juga patut dimasukkan dalam program persiapan Ustadz/Ustadzah karena Pancasila sebagai dasar negara menjadi alat dalam pemecahahan masalah baik dalam bidang ekonomi, budaya, keamanan, pendidikan dan masalah lainnya. Knowles (2018) menyatakan jika pandangan idiologi yang dimiliki guru akan selaras dengan apa yang mereka ajarkan. pembelajaran TPA di Wilayah Tambakboyo Yogyakarta di masa pandemi diharapkan dapat memberikan nilai yang bermanfaat bagi santri 
seperti yang dikatakan oleh Sukmayadi \& Suyitno (2020) bahwa nilai-nilai religius dapat dioptimalkan melalui TPA. Selain itu, Hidayah, Sapriya, Darmawan, Malihah, \& Karliani (2020) juga menegaskan jika sebagai warga negara yang baik, pengetahuan mengenai dasar negara menjadi salah satu kecerdasan warga negara.

\section{KESIMPULAN}

Dari kegiatan pengabdian manajemen TPA dan penguatan profil Pelajar Pancasila di Wilayah Tambakboyo Yogyakarta dapat disimpulkan bahwa terdapat peningkatan pengetahuan tentang manajemen TPA dan profil Pelajar Pancasila pada Ustadz/Ustadzah TPA di Wilayah Tambakboyo Yogyakarta. Selain itu, kegiatan pengabdian manajemen TPA dan penguatan profil Pelajar Pancasila di Wilayah Tambakboyo Yogyakarta juga mendapat animo yang positif dari masyarakat dan Kepala PCM di Wilayah Tambakboyo Yogyakarta. Implikasi pengabdian ini ialah Ustadz/Ustadzah TPA di Wilayah Tambakboyo mendapat pengetahuan mengenai manajemen TPA dan penguatan profil Pelajar Pancasila. Berdasarkan hasil pengabdian manajemen TPA dan penguatan profil Pelajar Pancasila, diharapkan agar kegiatan ini dapat berlangsung secara kesinambungan dan ada kegiatan monitoring pada Ustadz/Ustadzah TPA di Wilayah Tambakboyo Yogyakarta mengenai manajemen TPA dan profil Pelajar Pancasila. Dengan demikian, Ustadz/Ustadzah TPA di Wilayah Tambakboyo Yogyakarta dapat secara komperehensif mempraktikan manajemen TPA dan penguatan profil Pelajar Pancasila pada aktivitas pembelajaran di TPA masing-masing. Tantangan dalam pengabdian ialah adaptasi kebiasaaan baru dalam pola pembelajaran di TPA di Wilayah Tambakboyo Yogyakarta

\section{UCAPAN TERIMA KASIH}

Tim pengabdian mengucapkan terimakasih kepada: (1) Universitas Ahmad Dahlan Yogyakarta yang senantiasa memberikan fasilitas dan kesempatan agar terus bisa melakukan kegiatan pengabdian kepada masyarakat di tiap tahunnya; (2) Lembaga Penelitian dan Pengabdian kepada Masyarakat (LPPM) Universitas Ahmad Dahlan Yogyakarta yang telah memberikan dana untuk kegiatan ini, sehingga dapat dilaksanakan sesuai dengan jadwal dan sasaran kegiatan; dan (3) Kepala PCM di Wilayah Tambakboyo Yogyakarta yang telah berkenan menjadi mitra dalam pengabdian ini.

\section{REFERENSI}

Abe, A. (2005). Perencanaan Daerah Partisipatif. Yogyakarta: Pembaharuan.

Antara News.com. (2020). Mendikbud: Pendidikan karakter wujudkan Pelajar Pancasila. 2020. Retrieved from https://www.antaranews.com/berita/1824776/mendikbud-pendidikan-karakter-wujudkan-pelajar-pancasila

Chow, J. C., Granger, K. L., Broda, M. D., \& Peterson, N. (2020). Predictive Role of Classroom Management in Literacy Development in Preschool Children at Risk of EBD. Behavioral Disorders, 0198742920972322. https://doi.org/10.1177/0198742920972322

Collins, R. H., Sibthorp, J., \& Gookin, J. (2016). Developing IIl-Structured Problem-Solving Skills Through Wilderness Education. Journal of Experiential Education, 39(2), 179-195. https://doi.org/10.1177/1053825916639611

Daradjat, Z. (2008). Ilmu Pendidikan Islam. Jakarta: Bumi Aksara.

Dayal, H. C., \& Tiko, L. (2020). When are we going to have the real school? A case study of early childhood education and care teachers' experiences surrounding education during the COVID-19 pandemic. Australasian Journal of Early Childhood, 45(4), 336-347. https://doi.org/10.1177/1836939120966085

Entin, E. B., Entin, E. E., \& Hess, K. P. (2002). Development and Evaluation of an Information Management Training Program. Proceedings of the Human Factors and Ergonomics Society Annual Meeting, 46(25), 2012-2016. https://doi.org/10.1177/154193120204602503

Garcia, C., Argelagós, E., \& Privado, J. (2020). Assessment of higher education students' information problem-solving skills in educational sciences. Information Development, 0266666920976189. https://doi.org/10.1177/0266666920976189

Gilmour, A. F., Majeika, C. E., Sheaffer, A. W., \& Wehby, J. H. (2018). The Coverage of Classroom Management in Teacher Evaluation Rubrics. Teacher Education and Special Education, 42(2), 161-174. https://doi.org/10.1177/0888406418781918

Hamlen, K. R. (2017). General Problem-Solving Styles and Problem-Solving Approaches in Video Games. Journal of Educational Computing Research, 56(4), 467-484. https://doi.org/10.1177/0735633117729221

Hardré, P. L., Ling, C., Shehab, R. L., Nanny, M. A., Nollert, M. U., Refai, H., ... Wollega, E. D. (2013). Teachers in an Interdisciplinary Learning Community: Engaging, Integrating, and Strengthening K-12 Education. Journal of Teacher Education, 64(5), 409-425. https://doi.org/10.1177/0022487113496640

Henrickson Parker, S., Schmutz, J. B., \& Manser, T. (2018). Training Needs for Adaptive Coordination: Utilizing Task Analysis to Identify Coordination Requirements in Three Different Clinical Settings. Group \& Organization Management, 43(3), 504-527. https://doi.org/10.1177/1059601118768022

Hidayah, Y. (2020). Disertasi: pengembangan model belajar keterlibatan (MBK) untuk memperkuat partisipasi politik dan civic engagement warga negara muda di era digitaL. Bandung: Universitas Pendidikan Indonesia.

Hidayah, Y., Sapriya, Darmawan, C., Malihah, E., \& Karliani, E. (2020). Promoting Civic Intelligence in Applied Science to Promote Interaction between Science: An Overview in the Perspective of Citizenship Education. Universal Journal 
of Educational Research, 8(8). https://doi.org/10.13189/ujer.2020.080859.

Jackson, N., \& Miller, R. (2019). Teacher Candidates' Sense of Self-Efficacy Toward Classroom Management. Journal of Education, 200(3), 153-163. https://doi.org/10.1177/0022057419881169

Kabir, S. M. S. (2016). WRITING RESEARCH REPORT. In Chapter 13: Basic Guidelines for Research: An Introductory Approach for All DisciplinesEdition: First. Chittagong-4203: Book Zone Publication.

Khan, N., Tayal, S., \& Khalique, F. (2015). Understanding Management Development Techniques for Organization and Employee Growth: A Conceptual Study. Advances in Economics and Business Management (AEBM), 2(8), 800804. Retrieved from https://www.researchgate.net/publication/318440573_Understanding_Management_Development_Techniques _for_Organization_and_Employee_Growth_A_Conceptual_Study

Knowles, R. T. (2018). Ideology in the schools: Developing the teacher's Civic Education Ideology Scale within the United States. Education, Citizenship and Social Justice, 14(3), 260-278. https://doi.org/10.1177/1746197918800664

Kürzinger, M.-L., Douarin, L., Uzun, I., El-Haddad, C., Hurst, W., Juhaeri, J., \& Tcherny-Lessenot, S. (2020). Structured benefit-risk evaluation for medicinal products: review of quantitative benefit-risk assessment findings in the literature. Therapeutic Advances in Drug Safety, 11, 2042098620976951. https://doi.org/10.1177/2042098620976951

Lickona, T. (1991). Educating for Character, Mendidik untuk Membentuk Karakter. Jakarta: Bumi Aksara.

Liu, S., \& Hallinger, P. (2018). Principal Instructional Leadership, Teacher Self-Efficacy, and Teacher Professional Learning in China: Testing a Mediated-Effects Model. Educational Administration Quarterly, 54(4), 501-528. https://doi.org/10.1177/0013161X18769048

Mulyasa, E. (2008). Menjadi Guru Profesional Menciptakan Pembelajaran yang Kreatif dan Menyenangkan. Bandung: : PT Remaja Rosdakarya.

Piggot-Irvine, E., \& Zornes, D. (2016). Developing a Framework for Research Evaluation in Complex Contexts Such as Action Research. SAGE Open, 6(3), 2158244016663800. https://doi.org/10.1177/2158244016663800

Pokhrel, S., \& Chhetri, R. (2021). A Literature Review on Impact of COVID-19 Pandemic on Teaching and Learning. Higher Education for the Future, 8(1), 133-141. https://doi.org/10.1177/2347631120983481

Randell, R., Greenhalgh, J., Hindmarsh, J., Honey, S., Pearman, A., Alvarado, N., \& Dowding, D. (2019). How do team experience and relationships shape new divisions of labour in robot-assisted surgery? A realist investigation. Health, 25(2), 250-268. https://doi.org/10.1177/1363459319874115

Shamir-Inbal, T., \& Blau, I. (2021). Facilitating Emergency Remote K-12 Teaching in Computing-Enhanced Virtual Learning Environments During COVID-19 Pandemic - Blessing or Curse? Journal of Educational Computing Research, 0735633121992781. https://doi.org/10.1177/0735633121992781

Simonsen, B., Freeman, J., Myers, D., Dooley, K., Maddock, E., Kern, L., \& Byun, S. (2019). The Effects of Targeted Professional Development on Teachers' Use of Empirically Supported Classroom Management Practices. Journal of Positive Behavior Interventions, 22(1), 3-14. https://doi.org/10.1177/1098300719859615

Sudjana, N. (2009). Penilaian Hasil Belajar Mengajar. Bandung: PT. Remaja Rosdakarya.

Sukmayadi, T., \& Suyitno, S. (2020). Implementasi PPKn berbasis Nilai-nilai Islam di SD Muhammadiyah Kecamatan Depok Sleman Yogyakarta. JPK (Jurnal Pancasila Dan Kewarganegaraan), 5(1). https://doi.org/10.24269/jpk.v5.n1.2020.pp44-53

Yusuf, Y., \& Trisiana, A. (2019). Metode Braistorming Tertulis: Teknik Curah Pendapat Dengan Memaksimalkan Keterlibatan Semua Peserta Dalam Pengambilan Keputusan. Adiwidya: Jurnal Pengabdian Masyarakat Universitas Slamet Riyadi, 3(2). https://doi.org/10.33061/awpm.v3i2.3365 